\title{
AVALIAÇÃO DA INFLUÊNCIA DAS CONCEPÇÕES ALTERNATIVAS NO ENSINO E APRENDIZAGEM DA FÍSICA: UM ESTUDO DE CASO EM MOÇAMBIQUE
}

\author{
EVALUATION OF THE INFLUENCE OF ALTERNATIVE CONCEPTIONS IN THE \\ TEACHING AND LEARNING OF PHYSICS: A CASE STUDY IN MOZAMBIQUE
}

Jossias Arnaldo Vilanculo ${ }^{1}$
ORCID iD: $\underline{0000-0002-2677-1191}$

Inocente Vasco Mutimucuio ${ }^{2}$

ORCID iD: $\underline{0000-0001-8883-9027}$

Carlos Santos Silva ${ }^{3}$

ORCID iD: 0000-0002-7532-3993

\begin{abstract}
RESUMO
O presente trabalho relata os resultados de uma pesquisa que visa avaliar a influência da valorização das concepções alternativas dos alunos nos conceitos de calor e temperatura. Para concretização deste estudo, foi feito um levantamento na literatura das concepções alternativas mais comuns dos alunos. Em seguida, produziu-se um questionário que foi validado após a sua aplicação a 25 estudantes da $9^{\mathrm{a}}$ classe, com 7 perguntas abertas, das quais 5 foram retiradas da literatura e 2 elaboradas pelos autores. O questionário foi refeito com a reformulação de algumas questões e acréscimo de outras, tendo passado para 13 questões. O novo instrumento foi aplicado a 121 alunos de 2 turmas selecionadas aleatoriamente. As duas turmas foram submetidas a três aulas, nos quais na turma experimental valorizou-se as concepções alternativas dos alunos e na turma de controlo não se teve em consideração essas concepçõe. $\mathrm{O}$ resultado mostra que na turma experimental os alunos melhoraram significativamente a formulação dos conceitos científicos sobre calor e temperatura em relação à turma de controlo, tendo se concluído que a valorização destas no processo de ensino e aprendizagem é fundamental para a aprendizagem significativa, enfatizando Ausubel sobre a valorização do conhecimento prévio.
\end{abstract}

Palavras-chave: Concepções alternativas. Ensino e aprendizagem. Calor. Temperatura.

\footnotetext{
${ }^{1}$ Doutorando em Ciência e Tecnologias de Energias na Universidade Eduardo Mondlane (UEM). Docente na Universidade Save (UniSave), Chongoene, Gaza, Moçambique. Endereço para correspondência: Avenida FPLM, Bairro Cimento, Município de Massinga, Província de Inhambane, Moçambique, Caixa Postal 111. E-mail: jossianevilanculo1@yahoo.com.

${ }^{2}$ Professor Doutor em Física (Desenvolvimento do Conceito de Energia) pela Universidade Livre de Amsterdão, Holanda. Reitor na Universidade Wutivi (UniTiva), Boane, Maputo, Moçambique. Endereço para correspondência: Avenida da Namaacha no 188, Bairro 2, Belo Horizonte, Boane, Província de Maputo, Moçambique. E-mail: inocente.mutimucuio@gmail.com.

${ }^{3}$ Professor Doutor em Engenharia Mecânica pelo Instituto Superior Técnico (IST) da Universidade Técnica de Lisboa. Professor Auxiliar do Departamento de Engenharia Mecânica do Instituto Superior Técnico (IST) da Universidade Técnica de Lisboa, Lisboa, Portugal. Endereço para correspondência: Av. Rovisco Pais 1, 1049001 Lisboa, Portugal. E-mail: carlos.santos.silva @ tecnico.ulisboa.pt.
} 


\begin{abstract}
The present work describes the results of a research work that fosters the evaluation of the use of the students alternative conceptions regarding the heat and temperature concepts. The development of the research started with a detail literature review of the students most common alternative conceptions. Then, a questionnaire was done to 25 students of the $9^{\text {th }}$ grade in a school in Mozambique, with 7 open questions. These questions were both based in the literature (5) and developed by the authors of the research (2). The survey was later reformulated and expanded to 13 questions, to capture better the alternative conceptions. This new questionnaire was applied to 121 students from two different classes. Both classes were done used to present the concepts of heat ad temperature: in the experiment class, the teaching considered the alternative concepts, while in the control class, the teaching followed the traditional descriptive approach. The results clearly show that the students in the experiment class improved the formulation of heat and temperature concepts compared to the control class. Thus, it is concluded that the use of alternative conceptions in teaching is fundamental to develop a significative learning, emphasizing Ausubel theory of valorising previous knowledge.
\end{abstract}

Keywords: Alternative conceptions. Teaching and learning. Heat. Temperature

\title{
1. INTRODUÇÃO
}

Concepções alternativas são ideias iniciais usadas pelos alunos para explicar um determinado conceito ou fenómeno. Essas concepções divergem dos saberes científicos.

Apesar do estudo das concepções alternativas ser do domínio dos pesquisadores da área de ensino de ciências, os seus resultados são, ainda, pouco divulgados, fato que contribui para as dificuldades conceituais dos alunos.

Ao nível internacional, concepções alternativas sobre conceitos de calor e temperatura já foram desenvolvidas por Caldeira e Martins (1990), Cindra e Teixeira (2004), Grings, Caballero e Moreira (2008), Hoffmann, Nahirne e Strieder (2017), Hülsenderger, Costa e Cury (2006), Kohnlei e Peduzzi (2002), Leão e Kahil (2017), Louzada, Elia e Sampaio (2015), Mavanga (2007), Mutimucuio (1998), e outros. Em Moçambique, sobre esta abordagem, foram apenas publicados os trabalhos de Mavanga (2007) e Mutimucuio (1998).

As concepcões alternativas dos alunos podem orientar a prática pedagógica.Deste modo, conhecê-las ajuda para elaborar estratégias que possibilitarão novas representações e aquisição de um novo saber (LOBO; TRINDADE e CORDOVIL, 2017, p.236). A não valorização das concepções alternativas na sala de aulas contribui para a fraca assimilação dos conteúdos abordados por parte dos alunos. Na área de Termodinâmica, por exemplo, os alunos apresentam mais concepções alternativas nos conceitos de calor e temperatura. $\mathrm{Na}$ linguagem corrente, até os indivíduos instruídos cometem erros no uso dos conceitos calor e temperatura e vice-versa. 
A preocupação dos investigadores a respeito das concepções alternativas que os alunos traziam do ambiente em que viviam para a sala de aulas contribuiu para o surgimento, pela primeira vez, das pesquisas sobre concepções alternativas nos finais de 1970(LEÃO; KALHIL, 2015).

Segundo Hoffmann; Nahirne e Strieder (2017, p.93), "a década 80 representa o auge do movimento das concepções alternativas (MCA). A partir desta década surgem muitas pesquisas sobre a relação entre a aprendizagem e os saberes científicos, presentes na sala de aulas". Contudo, no período em referência, muitas pesquisas foram feitas no âmbito da mudança conceptual, cujo foco era em identificar os conceitos trazidos pelo aluno, corrigí-los ou substituí-los pelos conceitos cientificamente corretos.

Mais tarde, sob influência de Vygotsky e Ausubel, as concepções alternativas mantiveram a sua importância na aprendizagem até os dias de hoje. Apesar disso, em Moçambique, ainda há poucas publicações sobre a matéria.

O reduzido número de pesquisas científicas sobre concepções alternativas, em particular sobre os conceitos de calor e temperatura, motivou os pesquisadores a ocupar-se desta discussão, uma vez que suspeitam que os problemas de ensino e aprendizagem da Física nas escolas Moçambicanas, em particular na Escola Secundária "25 de Junho" de Massinga, sejam os mesmos identificados na literatura, ou seja, estejam relacionados com a não valorização das concepções alternativas dos alunos. Como ponto de partida, é definida a seguinte questão de pesquisa: Em que medida a valorização das concepções alternativas dos alunos contribui para uma aprendizagem significativa?

O objetivo da pesquisa é identificar e descrever as concepções alternativas dos alunos da $9^{\text {a }}$ classe sobre os conceitos de calor e temperatura e a sua influência no processo de ensino e aprendizagem. A pesquisa é parte da tese de doutoramento do primeiro autor deste artigo, a abordagem é de ponto de vista construtivista.

O trabalho está estruturado da seguinte maneira: na Introdução, tem-se a visão geral sobre o tema, o problema da pesquisa, a justificativa, o objetivo de estudo e o estado de arte; na a revisão da literatura, apresentam-se as concepções alternativas no ensino de ciências, sua origem e estudos realizados sobre concepções alternativas dos conceitos de calor e temperatura; depois se apresentam os materiais e métodos usados na pesquisa e, por fim, os resultados e considerações finais. 


\section{REFERÊNCIAL TEÓRICO}

\subsection{Concepções alternativas no ensino das ciências naturais}

Nos últimos anos, pesquisas desenvolvidas em ensino de Ciências Naturais, revelam a importância que as interacções entre professores e alunos podem ser um meio pelo qual os conhecimentos científicos são debatidos e compreendidos em sala de aula (CARVALHO; SASSERON, 2015).

$\mathrm{O}$ ensino de ciências naturais tem como objectivos gerais: compreender a natureza como um todo dinâmico e o ser humano como agente transformador; compreender que a ciência corresponde a um processo de produção de conhecimento e atividade humana e histórica; identificar as relações entre conhecimento científico, tecnologia e vida; compreender a saúde como bem individual e coletivo; formular questões e propor soluções para problemas reais; saber utilizar conceitos científicos básicos e combinar leituras e outros recursos de conhecimento; valorizar o trabalho colectivo com capacidade de criatividade e cooperação (RABER; GRISA e BOOTH, 2017).

Contudo, nas escolas Moçambicanas, tem se constado que alguns alunos terminam o seu nível de formação longe de alcançarem os objetivos anteriormente definidos, pois, não sabem utilizar alguns conceitos científicos básicos como é o caso de calor e temperatura. Estas dificuldades, provavelmente podem estar relacionadas pelo fato de os professores nas suas atividades de sala de aula, não tomarem em consideração as concepções alternativas dos alunos.

Diversas pesquisas, mostram que as concepções alternativas surgem e interferem no processo de ensino de ciências, constituindo-se em obstáculos de natureza epistemológica. Por tanto, a planificação de aulas de ciências naturais, assim como todo o material didático que é colocado á disposição dos alunos, não deve negligenciar as concepções alternativas dos alunos (ARAÚJO; SOUZA, 2015).

O conhecimento das concepções alternativas dos alunos é importante no processo de ensino e aprendizagem das ciências. Estas concepções assumem o papel central, porque todo o trabalho desenvolvido na aula deve estimular os alunos a apresentar, questionar e testar as suas ideias (BRUM; SCHUHMACHER, 2015).

Ausubel (1973) explica que:

A Aprendizagem Significativa é o processo pelo qual um novo conhecimento se relaciona de maneira não arbitrária e não literal à estrutura cognitiva do aluno, de modo que o conhecimento prévio do educando interaja, de forma significativa, com 
o novo conhecimento que lhe é apresentado, provocando mudanças em sua estrutura cognitiva (SILVA; SCHIRLO, 2014, p. 38).

A falta de interação das novas informações com ideias já ancoradas ou existentes, na estrutura cognitiva do indivíduo, a aprendizagem passa a ser apenas automática ou mecânica, ou seja, não haverá aprendizagem significativa (KRAUSE; SCHEID, 2018).

O aluno, quando chega à sala de aulas, traz uma concepção alternativa que deve ser modificada no decorrer da disciplina de ciências, mas, se os professores disconhecem os erros conceituais que aparecem nos livros didáticos, ou eles mesmos possuem concepções alternativas, a mudança conceitual e científica não acontecerá (LEÃO \& KALHIL, 2015).

De acordo com Hoffmann, Nahirne e Strieder (2017, p.92),

$\mathrm{Na}$ introdução a novos conteúdos nas aulas de ciências é importante que o professor estabeleça um diálogo com os alunos, questionando-os. Quando este é questionado [...], responde a partir de sua realidade, baseada nas informações que o mesmo adquire no dia-a-dia.

Uma estratégia de ensino mostra-se eficiente se considerar-se as concepções alternativas dos alunos sobre o que se pretende ensinar, caso contrário, os alunos terão dificuldades em assimilar novos conteúdos. Além disso, suas concepções alternativas permanecerão e outras, decorrentes das anteriores, poderão surgir (LOUZADA; ELIA E SAMPAIO, 2015). Neste caso, quando devidamente valorizadas, as concepções alternativas desempenham um papel importante no processo de ensino e aprendizagem das ciências. $\mathrm{O}$ professor precisa questionar sobre as concepções alternativas do aluno. Assim, o papel do professor passa a ser de um mediador na construção de conhecimento, através de um processo em que haverá no aluno interação entre o novo conhecimento e aquele que ele já possui.

Este processo ativa as concepções alternativas dos alunos para, depois, relacioná-las ao conteúdo inserido em sala de aulas (OLIVEIRA, 2005).

O processo de evolução conceitual, quando aplicado no contexto de ensino, promove uma aprendizagem significativa (MOREIRA; GRECA, 2003). A aprendizagem significativa parte do princípio de que todo sujeito carrega conhecimentos prévios ou concepções alternativas, chamados de subsunçores, que são usados como âncora para a assimilação de novos conhecimentos (MOREIRA, 1999). 


\subsection{Origem das concepções alternativas}

Sobre a origem das concepções alternativas, as pesquisas de Araújo e Souza (2015); Caldeira e Martins (1990); Hülsendeger, Costa e Cury (2006); Krause e Scheid (2018); Leão e Kalhil (2015); Mutimucuio (1998) convergem em afirmar que os modelos que os indivíduos usam para explicar conceitos e fenómenos físicos do dia-a-dia desenvolvem-se desde a infância, a partir do momento em que o indivíduo entra em contacto com a natureza, outros através do censo comum, não sendo originados exclusivamente do seu aprendizado escolar.

De acordo com Hoffmann, Nahirne e Strieder (2017, p. 98), “as ideias alternativas estão fortemente presentes, pois são influenciadas pelo contexto social e cultural, pelas linguagens dos meios de comunicação de massa”.

Para Mutimucuio (1998), a linguagem do dia-a-dia, onde os conceitos são explicados usando o censo comum; a cultura, onde os modelos que o indivíduo usa para explicar conceitos desenvolvem-se desde a infância, não sendo originados do seu aprendizado escolar e a influência da bibliografia, onde os manuais também apresentam erros na utilização de alguns conceitos, podem ser consideradas como causas das concepções alternativas nos alunos.

\subsection{Concepções alternativas dos estudantes nos conceitos de calor e temperatura.}

$\mathrm{Na}$ área da Termodinâmica, estudos realizados por vários autores tais como Caldeira e Martins (1990); Cindra e Teixeira, (2004); Hoffman, Nahirne e Strieder (2017); Hülsendeger, Costa e Cury (2006); Kohnlein e Peduzzi (2002); Louzada, Elia e Sampaio (2015); Valadares(1995) mostram as dificuldades dos alunos na formulação de conceitos de calor e temperatura.

A Tabela 2.1 apresenta algumas concepções alternativas retiradas da literatura:

Tabela 2.1- Síntese das concepções alternativas retiradas da literatura

\begin{tabular}{lll}
\hline \hline \multicolumn{1}{c}{ Concepção alternativa } & \multicolumn{1}{c}{ Fonte } & \multicolumn{1}{c}{ Comentários } \\
\hline \hline Calor é uma substância, & Louzada, Elia e Sampaio (2015); & Esta concepção é encontrada em frases \\
um fluido. & Caldeira e Martins (1990); Cindra e & como "vai ao banho para tirar calor [...]”. \\
& Teixeira, 2004; Hoffmann, Nahirne e & \\
& Strieder (2017); Köhnlein e Peduzzi \\
& $(2002)$. & \\
Calor é sinónimo do frio. & Louzada, Elia e Sampaio (2015); Encontra-se em frases do tipo “ no verão \\
& Caldeira e Martins (1990); Valadares & faz calor e no inverno faz frio”. \\
& (1995).
\end{tabular}


Calor e temperatura são a mesma coisa.

Calor associado a Caldeira e Martins (1990); temperatura elevada. Corpos quentes têm mais calor que corpos frios. Hoffmann, Nahirne e Strieder (2017). Hülsendeger, Costa e Cury (2006); Louzada, Elia e Sampaio (2015). Caldeira e Martins (1990); Valadares (1995); Köhnlein e Peduzzi (2002).

O tato pode determinar a
A temperatura é intensidade de calor.

\section{é} temperatura.

Temperatura pode ser transferida.

Louzada, Elia e Sampaio (2015); Cindra e Teixeira (2004); Hoffmann, Nahirne e Strieder (2017).

Louzada, Elia e Sampaio (2015); Caldeira e Martins, 1990; Hülsendeger, Costa e Cury (2006).

Louzada, Elia e Sampaio (2015).

A temperatura depende da natureza do material.
É comum na linguagem corrente alguém pronunciar "hoje está fazer muito calor, querendo dizer hoje a temperatura está elevada".

Quando alguém diz: “ amanhã será dia de muito calor pois a previsão é de $45^{\circ} \mathrm{C}$ ".

Existe uma concepção incorrecta de que entre corpos frios não há transferência de calor.

Erradamente existe a concepção de que temperatura elevada implica maior quantidade de calor.

Tem sido hábito usar erradamente o tato para avaliar a temperatura.

Quando dois corpos a temperaturas diferentes entram em contato, existe uma concepção errada de que há transferência de temperatura entre eles.

Existe uma concepção errada de que corpos de metal são mais frios que corpos de madeira estando no mesmo ambiente.

Fonte: elaborada pelo autor

\section{MATERIAIS E MÉTODOS}

A presente pesquisa assume uma abordagem qualitativa e quantitativa. " A Pesquisa quantitativa considera que tudo pode ser quantificável, o que significa traduzir em números opiniões e informações para classificá-las e analisá-las. Requer o uso de recursos e de técnicas estatísticas" (SILVA e MENEZES, 2005, p.20). Nesta abordagem, as respostas dos alunos são traduzidas em números para sua análise, ou seja, foi contabilizado o número de alunos por cada opção de resposta e expresso em frequência e percentagem no pré-teste e no pós-teste.

Por outro lado, na pesquisa qualitativa, de acordo com Gerhardit e Silveira (2009), o ambiente natural é a fonte direta para coleta de dados e o primeiro autor é instrumento-chave, sendo a interpretação dos fenómenos e a atribuição de significados elementos básicos no processo de pesquisa. Para o caso em concreto, um dos pesquisadores foi quem orientou as aulas de intervenção e na análise foram atribuídos significados às ideias iniciais dos alunos.

Quanto aos objectivos, a pesquisa é exploratória. Castilho, Borges e Pereira (2014) descrevem as pesquisas exploratórias como sendo geralmente bibliográfica, pois se avalia a possibilidade de desenvolver uma pesquisa sobre determinado assunto [...]. As pesquisas exploratórias oferecem informações sobre o assunto, definem os objectivos da pesquisa e orientam a formulação da hipótese. Nesta pesquisa, foi feita é revisão bibliográfica através do 
levantamento da literatura sobre pesquisas feitas em diferentes áreas da educação e ensino de física.

A amostra é proveniente de 2 turmas selecionadas aleatoriamente num universo de 19 do curso diurno. Foi usado o Microssof Excel, para gerar números aleatórios entre 1 a 19, tendo sido gerados números 10 e 11 . Assim, foram escolhidas as turmas 10 e 11 . As idades do grupo amostral estão entre 13 e 17 anos. Antes de serem submetidos, solicitou-se autorização aos pais e encarregados de educação numa reunião dirigida pelos diretores de turma. Os pesquisadores solicitaram autorização ainda á direção da escola através de uma carta formal

$\mathrm{O}$ estudo foi feito por meio de um questionário, aplicado para identificar e descrever as concepções alternativas dos alunos sobre os conceitos de calor e temperatura. Inicialmente, foi aplicado um questionário com 7 questões a alunos da $9^{\text {a }}$ classe, tendo levado 40 minutos para responderem. A partir das respostas dos alunos, foi elaborado um outro questionário onde algumas questões foram reformuladas; foi, ainda, revista a sequência ou tamanho das questões, ou seja, serviu para averiguar se mede o que se almeja medir (BRASIL et al., 2015). O novo instrumento foi composto por 13 questões, das quais 7 (sete) retiradas do trabalho de Mutimucuio (1998), e 6 (seis) de autoria própria. Destas questões, 7 (sete) são questões abertas e 6 (seis) questões fechadas, com opção justifique.

Nas seções em que pedia-se os conceitos de calor e temperatura, acrescentou-se uma questão para cada seção em que o aluno tinha explicar o conceito em sua língua materna. No novo instrumento, o aluno é solicitado para, primeiro, escrever o significado do conceito na sua língua materna. A questão 2 (dois) do estudo piloto que pedia para o aluno escrever uma frase, contendo a palavra calor, foi reformulada. No novo instrumento, pede-se para o aluno descrever um fenómeno do quotidiano que contenha a palavra calor. Estas alterações também foram feitas em relação ao conceito de temperatura. Para além das alterações descritas, todas as questões do primeiro instrumento foram inclusas no segundo instrumento. O instrumento foi aprovado por dois professores especializados na matéria, por sinal o supervisor e cosupervisor e, lido antes da aplicação por 2 docentes de Física da escola onde desenvolveu-se a pesquisa para avaliarem se a linguagem seria perceptível para os alunos. O questionário reformulado foi aplicado a 121 alunos da $9^{a}$ classe, dado que estes conceitos são abordados formalmente pela primeira vez nesta classe, tendo levado 75 minutos para o seu preenchimento.

Após a aplicação do pré-teste, as respostas da questão sobre o significado de calor na língua materna dos alunos foram categorizadas. A categorização foi inspirada nos modelos utilizados por outros pesquisadores da área de investigação em Ciências (COVOLAN; 
SILVA, 2005;MOÇO; SERRANO, 2002; NEVES, CHARRET; CARVALHO, 2017). A categoria $\mathrm{A}$, tem respostas que não apresentem indícios de concepções alternativas, com critérios válidos da concepção científica; a categoria $\mathrm{B}$, com respostas que apresentam algumas noções corretas, porém imprecisas e; a categoria $\mathrm{C}$, com concepção alternativa, ou resposta fora do contexto, ou ainda sem resposta. Em cada questão, cada categoria foi contabilizada e expressa em percentagem e, paralelamente, eram identificadas as concepções alternativas dos alunos.

A intervenção didática teve lugar 1 (uma) semana após o pré-teste. Na turma de controlo, foram dadas três aulas usando método expositivo, vulgo tradicional, o predominante na escola onde desenvolveu-se a pesquisa. Já na turma experimental, o mesmo número de aulas foram dadas com uma abordagem que centrou-se na valorização das concepções alternativas dos alunos a partir de atividades experimentais. A partir de uma ficha de atividades (Apêndice 5) adaptada a partir do trabalho de Pereira (2010), o professor (um dos pesquisadores) colocou questões em forma de problemas, de modo a procurar alcançar nos alunos situações de conflito cognitivo. A problematização das questões na turma experimental permitiu que os alunos manifestassem as suas concepções alternativas que eram contrariadas com as observações dos resultados experimentais, levando-os a ficar em situações de conflito cognitivo.

Sobre a estratégia usada na turma experimental, Sacate (2004, p. 5), descreve que na estratégia conflito cognitivo, "o aluno é submetido a uma situação em que as suas ideias prévias sobre determinado fenómeno são colocadas em conflito com fatos observáveis, isto é, as suas concepções alternativas são contrariadas por resultados experimentais”.

Para Ausubel, a valorização do conhecimento prévio ou concepções alternativas é factor chave para haver aprendizagem significativa (MOREIRA, 2011).

Nesta estratégia da turma experimental, o papel do professor foi fundamental. Conseguiu-se explorar as concepções alternativas dos alunos através da problematização das atividades. Foram submetidos em conflito cognitivo e, com a mediação do professor, conseguiram construir seu próprio conhecimento. Após a intervenção didática, 3 (três) depois aplicou-se o pós-teste constituído pelas mesmas questões do pré-teste.

\section{RESULTADOS}

Para este estudo, serão analisadas apenas questões relativas aos conceitos de calor e temperatura dos questionários. 


\subsection{Análise das respostas sobre o conceito de calor na língua materna dos alunos}

Na Tabela 4.1 são apresentados os resultados das respostas dos alunos na questão sobre o significado de calor na língua materna dos alunos.

Tabela 4.1- Análise das respostas à questão sobre o significado de calor na língua materna do aluno na turma de controlo.

\begin{tabular}{cccc}
\hline \hline Categoria & Nr de Estudantes & Percentagem & Concepções alternativas identificadas \\
\hline \hline A & 0 & 0 & Calor significa temperatura elevada \\
\hline B & 0 & 0 & \\
\hline C & 60 & 100 & \\
\hline \hline
\end{tabular}

Na turma de controlo, nas três línguas maternas, nomeadamente xitsua, guitonga e xichopi, o significado de calor é kuhissa, gu vissa e lissane ou lissane kunguetela ka kubissa respectivamente. Traduzido na língua portuguesa, os três termos significam temperatura elavada. Os 60 (sessenta) avaliados responderam a questão, tendo manifestado a concepção alternativa de que "calor significa temperatura elevada". A mesma análise foi feita para a turma experimental como pode-se ler na Tabela 4.2.

Tabela 4.2- Análise das respostas à questão sobre o significado de calor na língua materna do aluno na turma experimental.

\begin{tabular}{lccl}
\hline \hline Categoria & Nr de alunos & Percentagem & Concepções alternativas identificadas \\
\hline \hline A & 0 & 0 & Calor significa temperatura elevada \\
\hline B & 0 & 0 & Calor significa aquecimento \\
\hline C & 61 & 100 & \\
\hline \hline
\end{tabular}

Fonte: elaborada pelo autor

$\mathrm{Na}$ turma experimental, os alunos que responderam a questão se expressaram em duas línguas, xitsua e guitonga. Comparando com a turma de controlo, surge mais uma concepção alternativa respondida por 7 (sete) alunos, na língua xitsua que, para além do termo kuhissa colocaram outras respostas como пhисо, тити e ndzilu, que na língua portuguesa significam transpirar, dia ensolarado e fogo, respetivamente. Este pensamento foi associado a concepção alternativa de que "calor significa aumento da temperatura".

Duma forma geral, constatou-se que nas três línguas maternas mais faladas na província de Inhambane, xitsua, guitonga e xichopi, o termo "calor" significa temperatura elevada. Nesta questão, percebe-se que a língua materna dos alunos contribui para a origem 
das concepções alternativas sobre o conceito de calor. Esta constatação é referenciada por Mutimucuio (1998) que, de entre outros aspectos indicados como origem das concepções alternativas, indica as línguas maternas com uma das causas.

\subsection{Análise comparativa das respostas sobre os conceitos de calor e temperatura no pré-teste e pós-teste na turma de controlo.}

Após a intervenção didática, os alunos foram submetidos a um pós-teste. Os resultados são apresentados em tabelas comparativas entre a quantidade de concepções alternativas que os alunos manifestavam antes e depois da intervenção didática, em cada um dos dois conceitos (calor e Temperatura), nas duas turmas, nomeadamente turma de controlo e turma experimental.

A Tabela 4.3 mostra o resumo das concepções alternativas exibidas pelos alunos na turma de controlo sobre os conceitos de calor e temperatura no pré-teste e no pós-teste.

Tabela 4.3-Análise das respostas dos alunos nas questões sobre os conceitos de calor e temperatura na turma de controlo no pré-teste e pós-teste.

\begin{tabular}{|c|c|c|}
\hline Conceitos & $\begin{array}{c}\text { Concepções alternativas identificadas no } \\
\text { Pré-teste }\end{array}$ & $\begin{array}{c}\text { Concepções alternativas identificadas no } \\
\text { Pós-teste }\end{array}$ \\
\hline Calor & $\begin{array}{l}\text { Calor significa temperatura elevada. } \\
\text { Calor é energia. } \\
\text { Calor é medido da temperatura. } \\
\text { Calor é directamente proporcional } \\
\text { temperatura. } \\
\text { Calor é uma substancia ou fluido. } \\
\text { Calor é sinónimo de temperatura. } \\
\text { Calor é contrário de frio. }\end{array}$ & $\begin{array}{l}\text { Calor é energia. } \\
\text { Calor significa temperatura elevada. } \\
\text { Calor é uma substancia ou fluido. } \\
\text { Calor é contrário de frio. } \\
\text { Calor é sinónimo de temperatura. } \\
\text { Calor é directamente proporcional a } \\
\text { temperatura. }\end{array}$ \\
\hline Temperatura & $\begin{array}{l}\text { Temperatura é consequência de calor. } \\
\text { Temperatura significa calor. } \\
\text { A temperatura transfere-se. }\end{array}$ & $\begin{array}{l}\text { Temperatura é consequência de calor. } \\
\text { Temperatura significa calor. } \\
\text { A temperatura transfere-se. }\end{array}$ \\
\hline
\end{tabular}

Fonte: elaborada pelo autor

As concepções alternativas identificadas no pré-teste na turma de controlo foram: "calor significa temperatura elevada", “calor é energia", “calor é medido da temperatura", "calor é directamente proporcional a temperatura", "calor é uma substancia ou fluido", "calor é sinónimo de temperatura", "calor é contrário de frio", “ temperatura é consequência de calor", " temperatura significa calor" e "a temperatura transfere-se".

Estas concepções são as mesmas encontradas nos trabalhos de Silva (1995), Martins e Rafael (2002), Caldeira e Martins (1990), Köhnlein e Peduzzi (2002), Louzada, Elia e 
Sampaio (2015) e, Valadares (1995). Outra concepção identificada nesta questão é de que "calor é medida da temperatura " ou " calor é sinónimo temperatura" também descrita nos estudos feitos por Grings, Caballero e Moreira (2008).

Nota-se que relativamente ao conceito de "calor", os alunos manifestaram 7(sete) tipos de concepções alternativas no pré-teste e, 6(seis) tipos de concepções alternativas no pósteste. Este resultado, significa que não houve melhoria significativa na formulação do conceito de "calor" por parte dos alunos da turma de controlo. A concepção que não foi manifestada no pós-teste é a de que " calor é medida da temperatura”.

Em relação a formulação do conceito de "temperatura", o número e o tipo de concepções alternativas mantém-se, no pré-teste foram identificadas 3(três) concepções alternativas, as mesmas manifestadas no pós-teste. Foram identificadas as seguintes concepções alternativas: "temperatura é consequência de calor", "temperatura significa calor" e " a temperatura transfere-se". Também, assume-se que não houve melhoria após a intervenção didática.

O resultado obtido na turma de controlo, justifica-se com o argumento de Krause e Scheid (2018) quando afirmam que "em caso de não ocorrer a interacção das novas informações com ideias já ancoradas ou existentes, na estrutura cognitiva do indivíduo, a aprendizagem passa a ser apenas automática ou mecânica, ou seja não haverá aprendizagem significativa" (KRAUSE; SCHEID, 2018).

\subsection{Análise comparativa das respostas sobre os conceitos de calor e temperatura no pré-teste e pós-teste na turma experimental.}

Usando o mesmo procedimento da turma de controlo, é analisada a turma experimental no pós-teste através da Tabela 4.4.

Tabela 4.4-Análise das respostas dos alunos nas questões sobre os conceitos de calor e temperatura na turma experimental no pré-teste e pós-teste

\begin{tabular}{cll}
\hline \hline \multirow{2}{*}{ Calor } & Calor significa temperatura elevada. & \\
& Calor é energia. & Calor é energia. \\
& Calor é medido da temperatura. & Calor é contrário de frio. \\
& Calor é directamente proporcional a temperatura. & Calor é sinónimo de \\
& Calor é uma substancia, um fluido. & temperatura. \\
& Calor é sinónimo de temperatura. & \\
& Calor é contrário de frio. & A temperatura transfere-se. \\
\hline \hline \multirow{2}{*}{$\begin{array}{c}\text { Temperat } \\
\text { ura }\end{array}$} & Temperatura é consequência de calor. & \\
& Temperatura significa calor. & \\
\hline \hline
\end{tabular}

Fonte: elaborada pelo autor 
$\mathrm{Na}$ turma experimental os alunos manifestaram as mesmas concepções alternativas da turma de controlo no pré-teste. Sobre o conceito de "calor", os alunos exibiram 7 (sete) concepções alternativas, após a intervenção o número reduziu para 3 (três) concepções alternativas. Prevaleceram as concepções alternativas de que "calor é energia”, "calor é contrário de frio" e "calor é sinónimo de temperatura".

Sobre o conceito de “ temperatura", antes da intervenção didática os alunos manifestaram 3 concepções alternativas, após a intervenção didática, mantiveram 1 concepção alternativa, a de que "a temperatura transfere-se".

A concepção alternativa de que "a temperatura pode ser transferida" é descrita também nos estudos de Louzada, Elia e Sampaio (2015).

O resultado da turma experimental mostra que a estratégia usada permitiu aos alunos melhorarem a formulação dos conceitos de calor e temperatura após a intervenção didática.

De acordo com Louzada, Elia e Sampaio (2015), para que uma estratégia de ensino se mostre eficiente é necessário levar em conta as concepções alternativas sobre o que se pretende ensinar, caso contrário, os alunos terão dificuldades em assimilar novos conteúdos. O resultado confirma que a valorização das concepções alternativas através da estratégia de conflito cognitivo teve efeito na aprendizagem dos alunos.

\section{CONSIDERAÇÕES FINAIS}

As concepções alternativas existem em muitos conceitos da Física, sendo a Termodinâmica a área onde os alunos têm tido muitas concepções alternativas, muito por causa da utilização dos conceitos na língua materna, em que o calor é sinónimo de temperaturas altas. Em relação aos conceitos de calor e temperatura, as concepções alternativas mais comum dos alunos são: “calor significa temperatura elevada", "calor é energia", "calor é medida de temperatura", "calor é directamente proporcional à temperatura", "calor é uma substancia, um fluido", "calor é sinónimo de temperatura", "calor é contrário de frio", "temperatura é consequência de calor" e " a temperatura transfere-se".

Estas concepções alternativas coincidem com as identificadas na literatura, logo as concepções alternativas dos alunos da escola Secundária "25 de Junho" de Massinga, na Província de Inhambane, em Moçambique, são as mesmas exibidas por outros alunos internacionalmente.

Ao introduzir novos conceitos na sala de aulas, o professor deve ter a noção da existência de concepções alternativas nos alunos e, criar situações para que estas sejam 
exploradas na sala de aulas, de modo que os alunos tenham possibilidade de diferenciar saberes científicos e não científicos. Ao serem ignoradas as concepções alternativas, não haverá aprendizagem significativa dos conceitos.

A pesquisa mostra que a aprendizagem significativa tem lugar quando há valorização das concepções alternativas dos alunos, verificando, deste modo, a premissa de Ausubel, quando diz "o factor mais importante para que o aprendiz assimile novo conhecimento é quilo que ele sabe" (SILVA; 2020, p.3).

A pesquisa constitui um contributo para o ensino de física, em partícular para a Termodinâmica. O estudo teve como limitação o número reduzido de estudos publicados sobre concepções alternativas no ensino de Física em Moçambique nos últimos cinco anos, o levou os pesquisadores a recorrer à muitas fontes internacionais e, também à sua experiência de docência na área de Física.

\section{AGRADECIMENTOS}

Os nossos agradecimentos vão em primeiro lugar à Universidade Eduardo Modlane e em especial a Faculdade de Ciências por ter nos permitido fazer a pesquisa. Ao Ministério de Ciência, Tecnologia, Ensino Superior e Tecnico-Profissional de Moçambique, a Fundação Calouste Gulbenkian por terem financiado a pesquisa e ao Instituto Superior Técnico de Lisboa por ter contribuído para que a pesquisa chegasse ao fim.

Aos dr Afonso Pandzambilo e dr Olívio Mascarenhas, docentes de Física da Escola Secundária 25 de Junho pela cedência das turmas de controlo e experimental para a pesquisa.

Aos pais e encarregados de educação dos alunos da $9^{\text {a }} 10$ e $9^{\text {a }} 11$ que depositaram confiança em mim para trabalhar com seus filhos. Ao Mestre Hélder Matsule pela revisão linguística do texto.

\section{REFERÊNCIAS}

ARAÚJO, M. De, \& SOUZA, P. H. Conceitos, Concepções Alternativas E Ensino De Ciência : Uma Investigação Baseada Em Estudos Terminológicos. In: X Encontro Nacional de Pesquisa em Educação em Ciências. São Paulo, v. 1, n 8, nov. 2015. Disponível em: < http://www.abrapecnet.org.br/enpec/x-enpec/anais2015/resumos/R0530-1.PDF>. Acesso em: 03 Jun. 2018.

AUSUBEL, D. P. Algunos aspectos psicológicos de la estrutuctura del conocimiento. Buenos Aires: El Ateneo, 1973. 
BRASIL, M. V. O.; OLIVEIRA, F. C.; TASSIGUY, M. M., \& Ponpeu, R. M.Inovações sustentáveis em projetos de reresponsabilidade social. Revista Electronica Gestao \& Sociedade, v. 9, $n .22$, p.810-831, mar, 2015. Disponível em:<http://10.21171/ges.v9i22.2045>. Acesso em: 25 Fev. 2019.

BRUM, W. P.; SCHUHMACHER, E. O tema solo no ensino fundamental: Concepções altenativas dos estudantes sobre as implicações de sustentabilidade. Revista

Educomunicação Ambiental, v.5 n.1, p.1-22, 2015. Disponível em: < http://www.latec.ufrj.br/revistas/index.php?journal=eduambiental\&page=article\&op=view\&p ath\%5B\%5D=693 >. Acesso em 13 jun, 2019.

CALDEIRA, M. H.; MARTINS, D. R. Calor e Temperatura: Que noção tem os alunos universitários destes conceitos? Gazeta Fisica, v.13,n.2, p.85-94, 1990.

Disponívelem: <http://www.educadores.diaadia.pr.gov.br/arquivos/File/2010/artigos_teses/fisi ca/artigos/calor_temp_nocao_alunos_univ.pdf >. Acesso em 13 agost, 2019.

CARVALHO, A. M. P. de.; SASSERON, L. H. Ensino De Física Por Investigação: Referencial Teórico E As Pesquisas Sobre As Sequências De Ensino Sobre Calor E Temperatura. Ensino Em Revista, v.22 n.2, p.249-266, dez, 2015. Disponível em: <https://doi.org/10.14393/er-v22n2a2015-1>. Acesso em: 16 Jan. 2019.

CASTILHO, A. P.; BORGES, N. R. M.; PEREIRA, V. T. (Org.). Manual de metodologia científica do ILES. Itumbiara: ILES/ULBRA, 2014.

CINDRA, J. L.; TEIXEIRA, O., P., B. Uma discussão conceitual para o equilíbrio térmico. Caderno Brasileiro de Ensino de Física, v.21, n.2, p.176-193, 2004. Disponível em: <http://www.educadores.diaadia.pr.gov.br/arquivos/File/2010/artigos_teses/fisica/artigos/disc ussao_conceitual.pdf $>$. Acesso em: 28 Maio, 2019.

COVOLAN, T.; Silvia C.; Silva, D. da. A entropia no Ensino Médio: utilizando concepções prévias dos estudantes e aspectos da evolução do conceito. Ciência \& Educação (Bauru). v. 11, n. 1, p.97-117, Abr., 2005, ISSN: 1516-7313. Disponível em:

http://www.redalyc.org/articulo.oa?id=251019517009, Acesso em 26 de Setembro de 2020.

GERHALDT, T. E.; SILVEIRA, D. T. Métodos de Pesquisa. Editora, Universidade Federel do Grande Rio Sul, Brasil, 2009.

GRINGS, E. T. O., CABALLERO, C.; MOREIRA, M. A. Avanços e retrocessos dos alunos no campo conceitual da Termodinâmica. Revista Electrónica de Ensenanza de las Ciencias, v. 1, n.7, 2008. Disponível em: 〈https://www.lume.ufrgs.br/handle/10183/94785>. Acesso em: 17, Fev. 2020.

HOFFMANN, J. L.; NAHIRNE, A. P. \& STRIEDER, D. M. Um Diálogo Sobre as Concepções Presentes no Ensino de Ciências. Arquivos Do Museu Dinâmico

Interdisciplinar, Paraná, v. 21 n 3, p. 90-101, dez. 2017. Disponível em <http://www.periodicos.uem.br/ojs/index.php/ArqMudi/article/view/40944>. Acesso em: 14 dez, 2018.

HULSENDEGER, M. J. V. C.; COSTA, D. K. \& CURY, H. N. Identificação de concepções de alunos de ensino médio sobre calor e temperatura. Actas Cientiae, v.8, n.1, p.35-46, 
jan/jun, 2006. Disponível em: < http://www.periodicos.ulbra.br/index.php/acta/article/viewFile/106/99>. Acesso em: 28 jan. 2020.

KÖHNLEIN, J. F.K.; PEDUZZI, S. S. Um estudo a respeito das concepções alternativas sobre calor e temperatura. Revista Brasileira de Investigação Em Educação Em Ciências, v.3, n.2, p.84-96, 2002. Disponível em: 〈https://doi.org/10.1017/CBO9781107415324.004 >. Acesso em: 13 jun. 2018.

KRAUSE, J. C.; SCHEID, N. M. Concepções alternativas sobre conceitos básicos de física de estudantes ingressantes em curso superior da área tecnológica: um estudo comparativo.

Revista Espaço Pedagógico, v.25, n.2, p.227-240, mar, 2018. Disponível em: <https://doi.org/10.5335/rep.v25i2.8157>. Acesso em: $14 \mathrm{dez}, 2018$.

LEÃO, N. M. de M.; KALHIL, J. B. Concepções alternativas e os conceitos científicos : uma contribuição para o ensino de ciências. Latin-American Journal of Physics Education, v.9, n.4, p.2-4, dez, 2015. Disponível em: 〈http://www.lajpe.org/dec15/4601_Nubia.pdf>. Acesso em 20 dez, 2018.

LEÃO, N. M. de M.; KALHIL, J. B. Concepções Alternativas como obstáculos no EnsinoAprendizagem da disciplina Física. Latin American Journal of Science Education. v. 4, n. 22009, p.1-8, out., 2017. ISSN: 2007-9842. Disponivel em: http://www.lajse.org/nov17/22009_Menezes_2017.pdf, Acesso em: 2 de Novembro de 2019.

LOBO, H. B.; TRINDADE, D. S. A. da.; CORDOVIL, R. V. Ensino de Ciências Em Espaços não Formais à luz da Epistemologia Bachelardiana. REAMEC- Rede Amazónica de Educação em Ciências e Matemática, v. 5, n. 2, p. 235-248, jul/dez, 2017. ISSN: 23186674. Disponível em: http://periodicoscientificos.ufmt.br/ojs/index.php/reamec, Acesso em 16 de Setembro de 2020.

LOUZADA, A. N., ELIA, M. da F., \& SAMPAIO, F. F. Concepções alternativas dos estudantes sobre conceitos térmicos: Um estudo de avaliação diagnóstica e formativa. Revista Brasileira de Ensino de Fisica, v.37, n.1, 1508, mar, 2015. ISSN: 1806-9126. Disponível em: < https://www.scielo.br/pdf/rbef/v37n1/0102-4744-rbef-37-01-1508.pdf > Acesso em: 16 fev, 2020.

MARTINS, A. F.P.; RAFAEL, F. J. "Faz calor" em Mossoró?. Mossoró, Brasil, 2002. Disponível em: http://www.fep.if.usp.br/ profis/arquivos/vienpec/CR2/p907.pdf. Acesso em: 30, Jun. 2019.

MAVANGA, Gil. Fundamentos da Didáctica de Física. Universidade Pedagógica, Maputo, 2007. (não publicado).

MOÇO, M. C. C.; SERRRANO, A. S. Análise das Concepções alternbativas de estudadntes universitários de licenciatura em biologia após uso da internet. In: IV Encontro Nacional de Pesquisa em Educação em Ciências. Bauro, 2002. Disponível em: https://edisciplinas.usp.br/pluginfile.php/3403243/mod_resource/content/1/ORAL031.pdf, Acesso em: 13 de Junho de 2020.

MOREIRA, M. A. Aprendizagem significativa. Brasília: Editora da UnB, 1999. 
MOREIRA, M. A. Física de Partículas: uma abordagem conceitual e epistemológica. São Paulo: Editora Livraria da Física, 2011.

MOREIRA, M.A.; GRECA, I.M. Concept mapping and mental models. Meaningful Learning Forum, v.1, n.1, 2003.

MUTIMUCUIO, Inocente V. Improving Student's Understanding of Energy: A Study of the Conceptual Development of Mozambican First-Year University Students. Gaza:

Mozambique, 1998.

NEVES, J. A.; CHARRET, I. da C.; CARVALHO, S. A. Estudando a física do efeito estufa no $9^{\circ}$ ano: uma abordagem visando a aprendizagem significativa. Experiências em Ensino de Ciências. v. 12, n. 8, p. 66-87, 2017. Disponível em:

https://if.ufmt.br/eenci/artigos/Artigo_ID437/v12_n8_a2017.pdf, Acesso em: 14 de Fevereiro de 2020.

OLIVEIRA, S. S. De. Concepções alternativas e ensino de biologia : como utilizar estratégias diferenciadas na formação inicial de licenciados. Educar em Revista, n. 26, p.233-250, 2005. ISSN: 0104-4060. Disponível em:< https://www.scielo.br/pdf/er/n26/n26a16.pdf $>$. Acesso em: 13 out, 2019.

PEREIRA, M. M. Uma proposta para o ensino de calor e temperatura no ensino médio. 2010. Dissertação (Mestrado) - Universidade Federal do Rio de Janeiro, Instituto de Física, Programa de Pós-Graduação em Ensino de Física, Rio de Janeiro, 2010. Disponível em: https://www.if.ufrj.br/ pef/producao_academica/dissertacoes/2010_Marta_Maximo_Pereira/d issertacao_Marta_Maximo.pdf, Acesso em 26 de Setembro de 2020.

RABER, D. A., GRISA, A. M. C.; SCHMITZBOOTH, I. A. Aprendizagem Significativa no Ensino de Ciências: Uma Proposta de Unidade de Ensino Potencialmente Significativa Sobre Energia e Ligações Químicas 1. Aprendizagem Significativa Em Revista/Meaningful Learning Review, v.7, n.2, p.64-85, 2017. Disponível em: < http://www.if.ufrgs.br/asr/artigos/Artigo_ID116/v7_n2_a2017.pdf >. Acesso em $17 \mathrm{fev}, 2019$.

SACATE, A. R. Uma exploração de algumas estratégias para promover o desenvolvimento conceptual no domínio da electricidade. 2004. 91 f. Dissertação (Mestrado) - Universidade Eduardo Mondlane, Faculdade de Educação, Programa de PósGraduação em Edução em Ciências Naturais e Matemática, Maputo, 2004.

SILVA da, J. B. A teoria da Aprendizagem Significativa de David Ausubel: uma análise das condições necessárias. Research, Society and Development, v.9, n.4, mar., 2020.

SILVA, D. Estudo das Trajectórias Cognitivas de Alunos: no ensino da diferenciação dos conceitos de calor e temperatura. Tese (Doutorado). Universidade de São Paulo, Faculdade de Educação, São Paulo, 1995. Disponível em: < https://repositorio.usp.br/single.php?_id=000742317\&locale=en_US >. Acesso em: 14 Jun. 2020.

SILVA, E. L.; MENEZES, E. M. Metodologia da pesquisa e elaboração de dissertação. 4. ed. Florianópolis, 2005. 
SILVA, S. de C. R. da.; SCHIRLO, A. C. Teoria da aprendizagem significativa de Ausebel; reflexões para o ensino de física ante a nova realidade social. Imagens da Educação, v.4, n.1, 36-42, 2014. Disponível em:

http://periodicos.uem.br/ojs/index.php/ImagensEduc/article/view/22694/pdf. Acesso em: 5 fev, 2019.

VALADARES, J. A. C. S. Concepções Altenativas no Ensino da Fisica à luz da Filosofia da Ciência. Dissertação (Mestrado). Universidade Aberta, Lisboa, Portugal, 1995. Disponível $\mathrm{em}:<$ https://repositorioaberto.uab.pt/handle/10400.2/2520 >. Acesso em: 08 jun. 2019.

Submetido em: 10 de junho de 2020.

Aprovado em: 24 de setembro de 2020. 